\author{
Joonmo Choung \\ Se-Min Jeong
}

http://dx.doi.org/10.21278/brod70307

ISSN 0007-215X

eISSN 1845-5859

\title{
VEHICLE SECURING SAFETY ASSESSMENTS OF A KOREAN COASTAL CAR FERRY ACCORDING TO ACCELERATION PREDICTION APPROACHES
}

\author{
UDC 629.541.2:629.331:629.5.065.2 \\ Professional paper
}

\begin{abstract}
Summary
The capsize and subsequent sinking of a coastal car ferry occurred along the Korean coast, resulting in hundreds of casualties. The rapid course change of the ship might have forced improperly secured cargoes to rush to one side and accelerated the capsizing event. This paper provides a comparative study of vehicle securing safety assessments composed of evaluations of the external inertia forces and lashing strengths for a car and a truck. The external inertia forces were evaluated based on the IMO CSS (CSS approach) and rule-based maximum motion angles (RULE approach). Being a car ferry as a target ship, the sea states were collected along the most frequent seagoing routes of the target ship. Frequency domain seakeeping analyses (FSA approach) were carried out and then the long-term motion components were derived using the collected sea state data. The long-term motion components were put forward based on time domain seakeeping analyses (TSA approach). The TSA approach estimated the most optimistic external forces, while the CSS approach provided the most conservative external forces. Assuming the vehicles were secured symmetrically with four steel wires, the lashing strengths were derived. More numbers of lashing cables were required for the heavy vehicles when the CSS approach was applied, while other approaches predicted sufficient lashing strengths compared to exerted forces.
\end{abstract}

Key words: $\quad$ car ferry; acceleration; inertia force; vehicle securing; lashing

\section{Introduction}

The sinking of a Korean coastal car ferry in 2014 caused more than 300 deaths. Cargoes including vehicles were not secured properly in the car ferry and a sudden course change might have induced a rush of general cargoes and cars. This motivated a review of the importance of vehicle stowage and securing in a car ferry.

The lashing rules on container cargoes are well defined in references such as a ship rule [1]. Hwang et al. [2] examined the container lashing technique, in which different types of lashing equipment were used. Shin and Hwang [3] performed the container stowage optimization based on a genetic algorithm. 
On the other hand, there have been few studies on the securing of general cargoes and vehicles. Turnbull and Dawson [4] suggested a mathematical model for calculating the trailer lashing forces. A classification society, DNV, developed and distributed an Excel macro called LashCon [5] that made it possible to estimate the cargo securing safety based on International Maritime Organization (IMO): Code of safe practice for cargo stowage and securing (CSS, [6]).

IMO [6] suggested a systematic procedure to assess the cargo securing safety in terms of the external inertia forces and lashing strengths. The IMO CSS suggested the tabulated acceleration components of ocean-going vessels when calculating the external inertia force components. Considering coastal liners are subjected to less motion-induced acceleration than ocean-going ones, IMO CSS is expected to provide more conservative inertia forces for car ferries sailing within the coastal area. This is the fundamental motivation for carrying out this study. The so-called direct load approach (DLA) were applied to a Korean coastal car ferry to evaluate conservancy of IMO CSS code.

In this paper, a car ferry with the displacement of 1,633 tonf, which has been a coastal liner, was selected as the target vessel. The main voyage routes of Korean coastal car ferries were also investigated to collect sea state data. The short-term sea data were collected from the sea observation buoys and stations close to main voyage routes for 64 months and a longterm wave scatter diagram was newly constructed. To predict the motion and hydrodynamic forces, which are necessary to estimate lashing strength, of a floating body in waves, experimental and numerical analysis can be applied. Among them, the numerical simulations based on the potential theory have been generally performed in frequency domain [7] or time domain [8] since they are less expensive than other methods but give proper results expect for the cases when non-linear viscous effects are important. In this study, both frequency and time domain hydrodynamic analyses were carried out to determine how much long-term motion components would be developed in the vehicles loaded in the car ferry. These approaches are called the frequency domain seakeeping analysis (FSA approach) and the time domain seakeeping analysis (TSA approach), respectively. The FSA- and TSA-based longterm motion components for the car ferry were derived using the wave scatter diagram.

Some ship rules, such as KR-Rules [9], suggest the maximum roll and pitch angles which can be used for calculating the motion-induced acceleration components. External force components can be predicted using these long-term acceleration components; hence, this approach is called the RULE approach. The RULE-based long-term acceleration components were also provided in this study.

The lashing safeties of a 0.96 tonf car and a 39 tonf truck were evaluated. The car and truck are believed to experience the largest roll acceleration because they were stowed on the farthest side of the ship. This paper calculates the external force components according to the four approaches. The lashing strengths were evaluated using LashCon [5] and LashingSafety by Jo et al. [10]).

\section{Target vessel and vehicles}

\subsection{Target vessel}

The target ship was a coastal car ferry built in a Korean shipyard. Table 1 lists the principal dimensions. In this paper, the full load condition was taken into account for seakeeping analyses, since a survey on the navigation records showed that the full load condition shares a large portion between two typical loading conditions: full load and ballast conditions. 
Table 2 provides information on the mass and center of mass (COM), where the longitudinal center of mass (LCOM) and vertical center of mass (VCOM) were measured from after the perpendicular (AP) and baseline (BL).

Table 1 Principal dimensions of the coastal car ferry

\begin{tabular}{|c|c|}
\hline Item & Dimensions \\
\hline Length overall, $L_{O A}(\mathrm{~m})$ & 69.76 \\
\hline Length between perpendiculars, $L_{B P}(\mathrm{~m})$ & 56.00 \\
\hline Breadth molded, $B_{m}(\mathrm{~m})$ & 14.0 \\
\hline Depth molded, $D_{m}(\mathrm{~m})$ & 3.50 \\
\hline Mean draught at full load, $T_{f}(\mathrm{~m})$ & 2.65 \\
\hline Full load displacement, $\Delta_{f}($ tonf $)$ & 1632.90 \\
\hline
\end{tabular}

Table 2 Principal dimensions of the coastal car ferry

\begin{tabular}{|c|c|c|}
\hline Item & Ballast & Full load \\
\hline Mass of lightship, $W_{L}$ (ton) & 1111.50 & 1111.50 \\
\hline Mass of deadweight, $W_{D}($ ton $)$ & 282.95 & 521.40 \\
\hline $2^{\text {nd }}$ moment of mass, $I_{x}\left(\right.$ ton- $\left.{ }^{2}\right)$ & $3.57 \mathrm{E} 10$ & $3.97 \mathrm{E} 10$ \\
\hline $2^{\text {nd }}$ moment of mass, $I_{y}\left(\right.$ ton- $\left.{ }^{2}\right)$ & $3.56 \mathrm{E} 11$ & $4.16 \mathrm{E} 11$ \\
\hline $2^{\text {nd }}$ moment of mass, $I_{z}\left(\right.$ ton- $\left.{ }^{2}\right)$ & $3.25 \mathrm{E} 11$ & $3.76 \mathrm{E} 11$ \\
\hline $\operatorname{LCOM}(m)$ & 26.30 & 27.3 \\
\hline $\operatorname{VCOM}(m)$ & 5.18 & 5.30 \\
\hline
\end{tabular}

\subsection{Target vehicles}

The ferry can load 5 heavy trucks and 22 cars for which the masses are 39 tonf and 0.96 tonf, respectively. Fig. 1 shows the main deck plan with the loaded heavy trucks and cars in the fore and after parts, respectively.

Two vehicles, a car and a truck, in the red rectangle lines in Fig. 1 were taken into account because they are located on the farthest port side and expected to be subjected to most extreme roll acceleration.

The spatial locations can be defined using the distance components of $r_{x}, r_{y}$, and $r_{z}$ from the center of ship mass $G$, as delineated in Fig. 2. Table 3 provides detailed information on the two vehicles including the masses, sizes and locations.

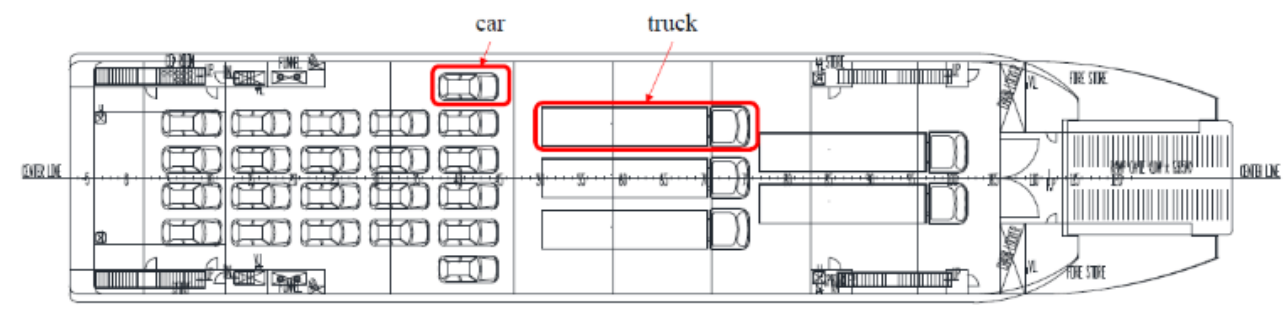

Fig. 1 Upper deck plan with cars and trucks loaded for full load condition 


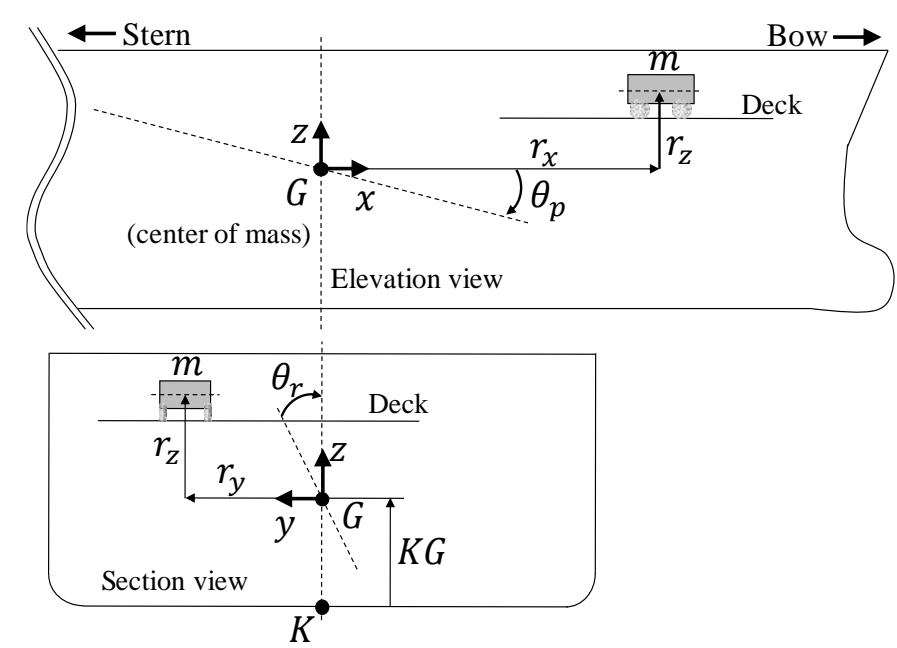

Fig. 2 Illustration for cargo stowed at bow and port sides

Table 3 Information on the two vehicles

\begin{tabular}{|c|c|c|}
\hline Item & Car & Truck \\
\hline$m($ ton $)$ & 0.91 & 39.00 \\
\hline$C_{x}(\mathrm{~m})$ & 3.60 & 12.62 \\
\hline$C_{y}(\mathrm{~m})$ & 1.60 & 2.50 \\
\hline$G_{c z}(\mathrm{~m})$ & 0.74 & 1.57 \\
\hline$r_{x}(\mathrm{~m})$ & 7.27 & 3.47 \\
\hline$r_{y}(\mathrm{~m})$ & 5.49 & 3.09 \\
\hline$r_{z}(\mathrm{~m})$ & 0.24 & 0.24 \\
\hline
\end{tabular}

\section{COMPARISON OF THE EXTERNAL FORCES}

\subsection{CSS Approach}

Neglecting wind pressure and sea water sloshing pressure, the IMO CSS suggests translational force components of $F_{x}, F_{y}$ and $F_{z}$ as delineated in Eqs. (1)-(3), where $f_{V L}$ and $f_{B G M}$ are the acceleration correction factors as functions of the ship speed to length ratio and ship breadth to metacentric height ratio, respectively. $a_{x}^{\prime}, a_{y}^{\prime}$, and $a_{z}^{\prime}$ are the tangential acceleration components in longitudinal, transverse, and vertical directions, respectively (see Fig. 4). $a_{x}^{\prime}$ and $a_{y}^{\prime}$ include the gravitational acceleration component, while $a_{z}^{\prime}$ is the pure motion-induced acceleration component. $F_{z}$ in Eq. (3) is a vertical force component. The transverse force, $F_{y}$, with a combination of moment arm, $G_{c z}$, can induce the tipping moment, $M_{x}$, regarding the tipping line, as shown in Fig. 3, where $x^{\prime}, y^{\prime}$, and $z^{\prime}$ are the local coordinate directions with the origin at the rear wheel axis, centerline, and the bottom of a vehicle. In addition, $\mathrm{m}, G_{c}, C_{x}$, and $C_{y}$ imply the mass, vertical center of mass, wheelbase, and tread of a vehicle. 


$$
\begin{aligned}
& F_{x}=m a_{x}=m\left(f_{V L} a_{x}^{\prime}\right) \\
& F_{y}=m a_{y}=m\left(f_{V L} f_{B G M} a_{y}^{\prime}\right) \\
& F_{z}=m a_{z}=m\left(f_{V L} a_{z}^{\prime}\right) \\
& M_{x}=F_{y} G_{c z}
\end{aligned}
$$

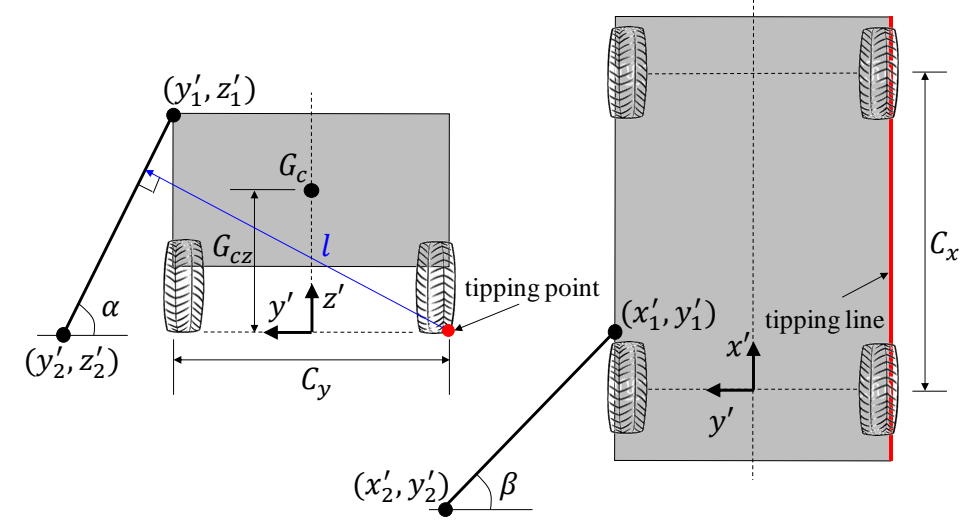

Fig. 3 Sketch for a vehicle secured by a wire

Fig. 4 shows the translational acceleration components defined in IMO CSS code [6]. Longitudinal locations of the car and truck were assumed to be 0.4 and 0.6 in Fig. 4, respectively. In addition, the vertical locations were thought to be at the tween-deck in Fig. 4. $f_{B G M}$, which is presented in tabular form can also be expressed by polynomials, as shown in Fig. 5.

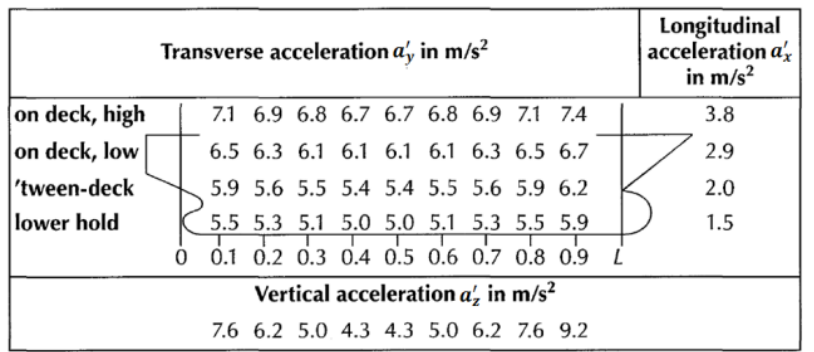

Fig. 4 Translational acceleration data defined in IMO CSS(IMO, 2011)

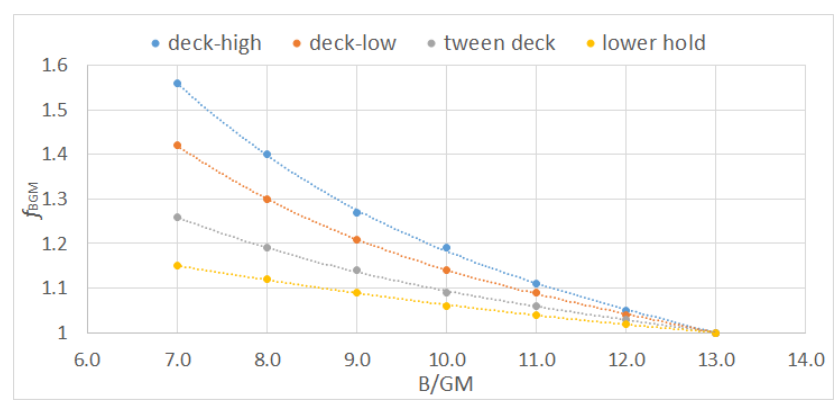

Fig. 5 Polynomial regression of $f_{B G M}$ 


\subsection{RULE Approach}

According to IMO CSS, $F_{x}$ and $F_{y}$ are induced mainly by pitch and roll motion components, respectively, but the gravitational acceleration components of $g_{x}$ and $g_{y}$ can contribute to increasing $F_{x}$ and $F_{y}$, as shown in Eqs. (5)-(6). The vertical force component, $F_{z}$, is caused by the heave-, pitch- and roll-induced acceleration components $\left(a_{h z}, a_{p z}\right.$ and $a_{r z}$ ), respectively, as delineated in Eq. (7). $\theta_{r}$ and $T_{r}$ are the roll angle and period, while $\theta_{p}$ and $T_{p}$ are the pitch angle and period, respectively. As depicted in Fig. $2, r_{x}, r_{y}$, and $r_{z}$ are the longitudinal, transverse, and vertical distances from ship mass center $(G)$ to vehicle mass center $\left(G_{c}\right)$. Common acceleration parameter, $a_{0}$, in Eq. (8) is taken from the classification society rules (DNV-GL, [5]). The RULE approach uses the same tipping moment, as shown in Eq. (4).

$$
\begin{aligned}
& F_{x}=m a_{x}=m\left(g_{x}+a_{p x}\right)=m\{\underbrace{g \sin \theta_{p}}_{g_{x}}+\underbrace{\left(\frac{2 \pi}{T_{p}}\right)^{2} \theta_{p} r_{z}}_{a_{p x}}\} \\
& F_{y}=m a_{y}=m\left(g_{y}+a_{r y}\right)=m\{\underbrace{g \sin \theta_{p}}_{g_{x}}+\underbrace{\left(\frac{2 \pi}{T_{p}}\right)^{2} \theta_{p} r_{z}}_{a_{p x}}\} \\
& F_{z}=m a_{z}=m\left(a_{h z}+a_{p z}+a_{r z}\right)= \\
& m\{\underbrace{0.8\left(1.15-\frac{6.5}{\sqrt{g L_{B P}}}\right) a_{0} g}_{a_{h z}}+\underbrace{\left(\frac{2 \pi}{T_{p}}\right)^{2} \theta_{p} r_{x}}_{a_{p z}}+\underbrace{\left(\frac{2 \pi}{T_{r}}\right)^{2} \theta_{r} r_{y}}_{a_{r z}}\} \\
& a_{0}=\left(1.58-0.47 C_{b}\right)\left(\frac{2.4}{\sqrt{L_{B P}}}+\frac{34}{L_{B P}}-\frac{600}{L_{B P}^{2}}\right)
\end{aligned}
$$

According to the ship rules of a classification society (KR, 2016), the maximum angles for roll and pitch motions $\left(\theta_{r}\right.$ and $\theta_{p}$ ) should be $25^{\circ}$ and $5^{\circ}$, respectively. The maximum periods for roll and pitch motions $\left(T_{r}\right.$ and $\left.T_{p}\right)$ are also expressed by Eqs. (9) and (10), where GM is the metacentric height. The translational acceleration components can be derived by substituting the determined $\theta_{r}, \theta_{p}, T_{r}$, and $T_{p}$ into Eqs. (5)-(7). The tipping moment component can be determined easily using Eq. (4). The RULE approach calculations were carried out using LashingSafety [10]. 


$$
\begin{aligned}
& T_{r}=\frac{0.7 B_{m}}{\sqrt{G M}} \\
& T_{p}=\frac{1}{2} \sqrt{L_{B P}}
\end{aligned}
$$

\subsection{FSA Approach}

As shown in Fig. 6, Incheon to Jeju, Busan to Jeju, Donghae to Ulung, and Pohang to Ulung are the main voyage routes in Korea [9]. Four ocean stations of Boksacho, Gyoboncho, Wangdolcho, and Ssangjeongcho are the closest ones from the main voyage routes. Therefore, the sea states at the locations were collected from the Korea Hydrographic and Oceanographic Agency (KHOA) for longer than 5 years from January in 2010 to April in 2015. Each dataset consists of a significant wave height $H_{s}$ and significant wave period $T_{s}$ for one hour measurement.

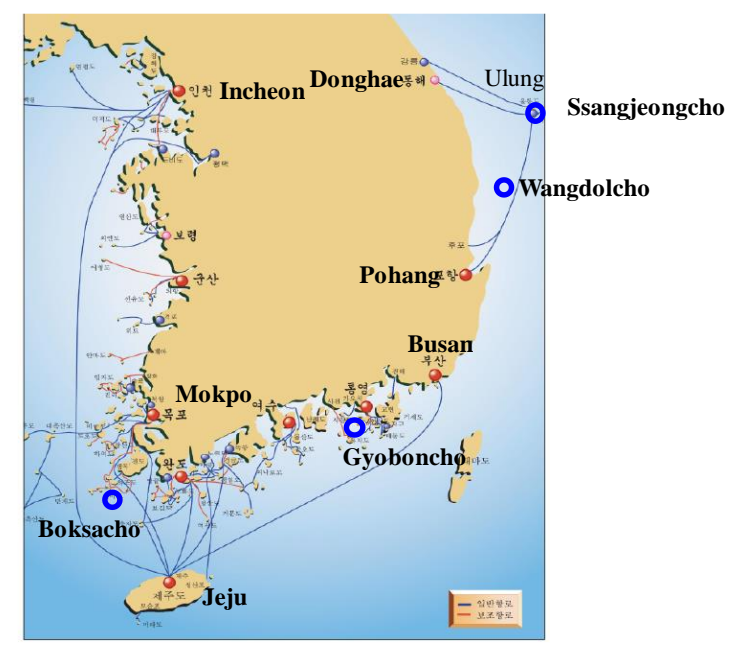

Fig. 6 Main voyage routes with the locations of the ocean stations

The significant wave period can be converted to zero up-crossing period $T_{z}$ using Eq. (11) by Kim [11]. Table 4 lists a newly constructed wave scatter diagram (WSD) according to $H_{s}$ and $T_{z}$, where sea states less than an occurrence probability of $1 \%$ were discarded.

$$
T_{z}=(4 / 5)^{0.25} \cdot T_{s}
$$

Considering the computing limits, the increment of wave incident angles was determined to be $22.5^{\circ}$. Each incident angle was assumed to have the same occurrence probability. The forward speed of 10 knots $(5.144 \mathrm{~m} / \mathrm{s})$ was also applied to frequency response analyses considering the normal continuation rate (NCR) of the car ferry. The forward speeds for the following and quartering seas were reduced so that the encounter frequencies were kept positive. The range and number of frequencies can determine how well the frequencies describe the real wave spectrum in terms of the $0^{\text {th }}$ order spectral moments (area of spectrum) and spectrum shapes for two extreme sea states of \#1 with the shortest $T_{z}(3.0 \mathrm{~s})$ and \#11 with the longest $T_{z}(11.0 \mathrm{~s})$. Fifty frequencies (49 increments) in total were applied to frequency response analyses, where the minimum and maximum frequencies were $0.1 \mathrm{rad} / \mathrm{s}$ and $4.850 \mathrm{rad} / \mathrm{s}$. Table 5 lists the drafts at after perpendicular (AP) and fore 
perpendicular (FP) and number of panels for the full loading condition. The two panel models for the loading condition were produced for frequency response analysis (refer to Fig. 7). A large sized-commercial vessel has a bilge keel to mitigate the roll motion so the viscous roll damping ratio, $\zeta$, is usually larger than $5 \%$. Because there is no information on the roll damping ratio of the car ferry, a viscous roll damping ratio of $2.5 \%$ was assumed in this paper. As shown in Eq. (12), the roll damping constant $b_{\text {roll }}$ was calculated using the roll damping ratio. In equation (12), $I_{x}$ and $I_{x a}$ mean second moments of masses about roll axis corresponding to initial displacement and added mass, respectively. $k_{x}$ means rotational stiffness with respect to roll axis. $I_{x}, I_{x a}$, and $k_{x}$ are functions of frequency, so values at the roll resonance frequency were used.

With the panel models and environmental data described above, frequency response analyses were conducted to calculate the radiation and wave excitation coefficients [12].

$$
b_{\text {roll }}=2 \zeta \sqrt{\left(I_{x}+I_{x a}\right) \times k_{x}}
$$

Table 4 Newly constructed wave scatter diagram

\begin{tabular}{|c|c|c|c|}
\hline Sea state & $H_{s}$ & $T_{s}$ & Prob. \\
\hline 01 & 0.5 & 3.0 & 0.1123 \\
\hline 02 & 0.5 & 5.0 & 0.2839 \\
\hline 03 & 0.5 & 7.0 & 0.2231 \\
\hline 04 & 0.5 & 9.0 & 0.0644 \\
\hline 05 & 0.5 & 11.0 & 0.0215 \\
\hline 06 & 1.5 & 5.0 & 0.0392 \\
\hline 07 & 1.5 & 7.0 & 0.1237 \\
\hline 08 & 1.5 & 9.0 & 0.0777 \\
\hline 09 & 1.5 & 11.0 & 0.0153 \\
\hline 10 & 2.5 & 9.0 & 0.0272 \\
\hline 11 & 2.5 & 11.0 & 0.0117 \\
\hline
\end{tabular}

Table 5 Information on the panels for the full loading condition

\begin{tabular}{|c|c|c|}
\hline \multirow{2}{*}{ Information } & Quantity \\
\hline \multirow{2}{*}{ Number of panels } & Wet part & 6699 \\
\cline { 2 - 3 } & Dry part & 124 \\
\hline \multirow{2}{*}{ Draft(m) } & at after perpendicular & 2.646 \\
\cline { 2 - 3 } & at fore perpendicular & 2.646 \\
\hline
\end{tabular}




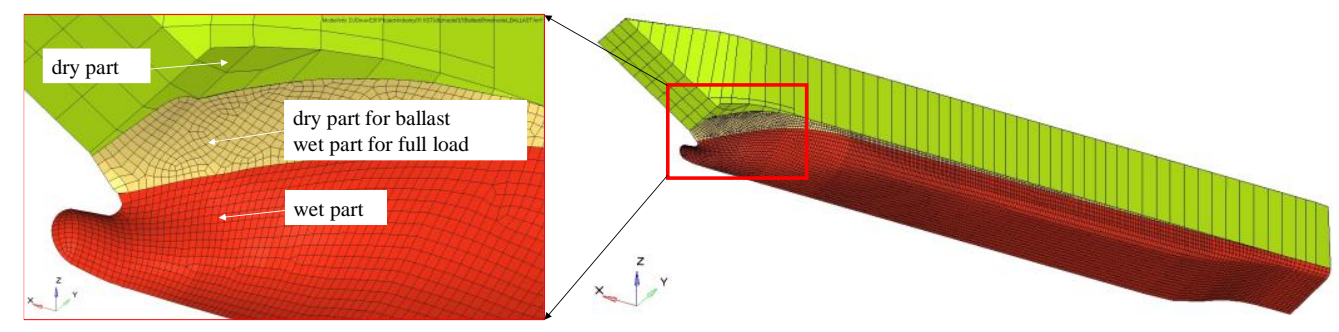

Fig. 7 Panels for two loading conditions

Fig. 8 presents the roll and pitch motion RAOs for full load conditions. These RAOs were used to calculate the long-term motion components. Using the linear order Volterra series shown in Eq.(13), a wave spectrum $S_{w}(\omega)$ can be the motion spectrum $S_{m}(\omega)$ for each wave incident angle. After deriving the zero order spectral moment $m_{0}$ of a motion component from $S_{m}(\omega)$, the effect of short crested waves was taken into account using the cosine square spreading function, $f(\phi)$, as delineated in Eq. (14). Let the long-term probability level be $1.0 \times 10^{-8}$ corresponding to 20 years, then the long-term motion components can be derived using Eq. (15), where $p, x$, and $x_{0}$ are the probability of exceedance, motion component, and target motion component. The predicted long-term roll and pitch components were $41.07^{\circ}$ and $12.26^{\circ}$, respectively.

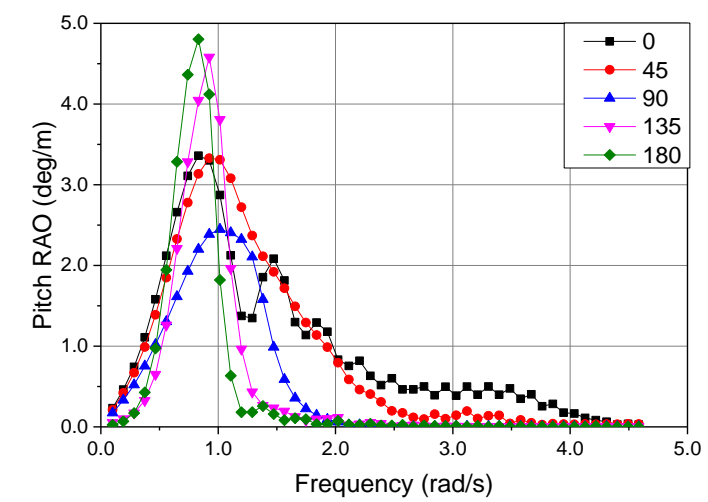

(a) Roll

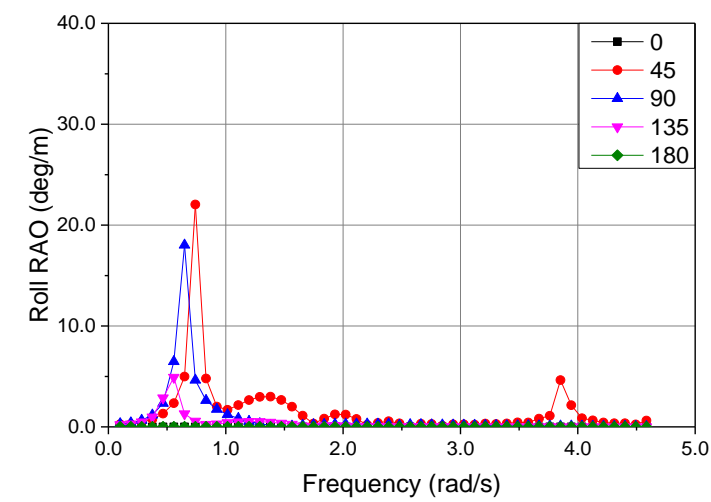

(b) Pitch

Fig. 8 RAOs from frequency response analyses

$$
\begin{aligned}
& S_{m}(\omega)=R A O^{2} \cdot S_{w}(\omega) \\
& f(\phi)=K \cdot \cos ^{2} \phi \\
& p\left(x \geq x_{0}\right)=e^{-\frac{x_{0}^{2}}{2 m_{0}}}
\end{aligned}
$$

where $\phi$ and $K$ are the wave incident angles around the central incident angle and spreading coefficient. 


\subsection{TSA Approach}

The Cummins equation (Cummins, 1962) provides a numerical technique to solve the equations of motion for a floating body in the time domain with radiation coefficients and wave excitations determined from frequency response analyses. This means that any probable nonlinear effect from wave excitation forces cannot be taken into account, but the nonlinear effect due to the wave amplitude in way of mean water level is considered [12].

The maximum frequency of $4.585 \mathrm{rad} / \mathrm{s}$ forces the time increment to be $0.2 \mathrm{~s}$. The time duration for each analysis case was decided to be one hour after comparing the statistical properties, such as the average and variance of peak distribution of a motion component between the one hour and two and half hour durations.

The ISSC standard wave spectrum was introduced to produce random wave excitation in the time domain seakeeping analyses. Considering the 11 sea states and 9 wave directions, 99 time domain analyses were conducted for each loading condition.

Fig. 9 shows the time response analysis results for sea state \#10, which has the highest significant wave height. Time processes and spectra of the pitch motion component are shown for direction of $180^{\circ}$ while the roll component results are depicted for the direction of $45^{\circ}$. To verify the validity of the time processes, the motion RAOs and wave spectrum were plotted together with the motion spectra. The resonance frequencies for the roll and pitch RAOs coincided relatively well with the response spectra, as delineated in Fig. 9 (a) and (b).
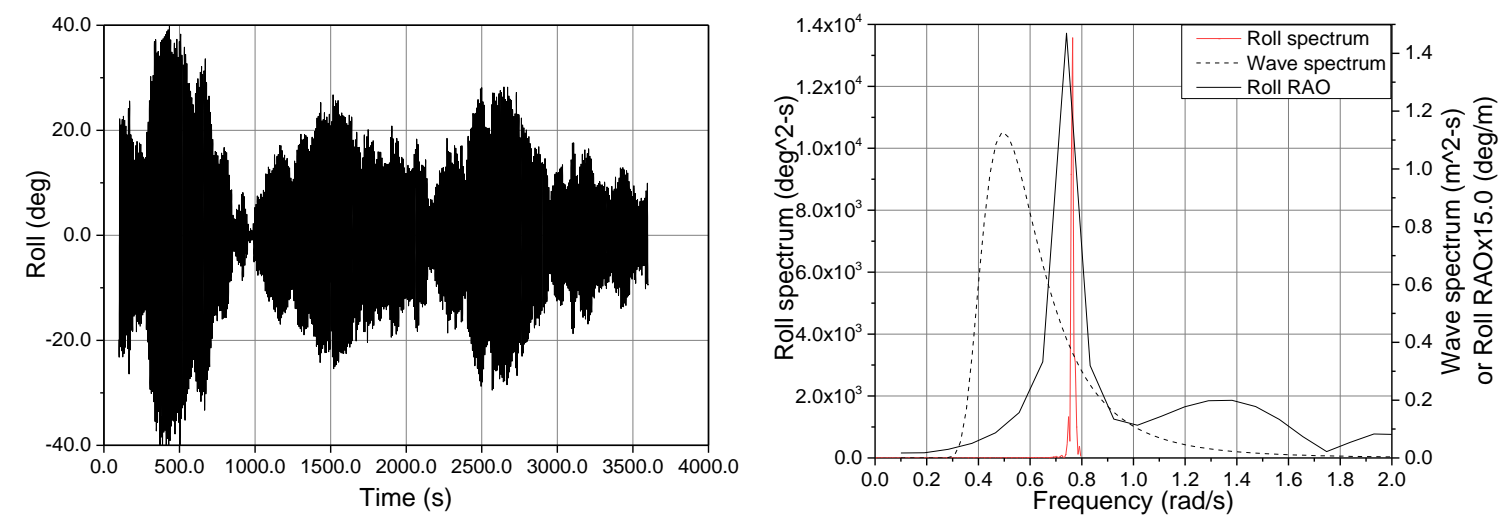

(a) Roll history, roll spectrum, wave spectrum, and roll RAO for a wave direction of $45^{\circ}$
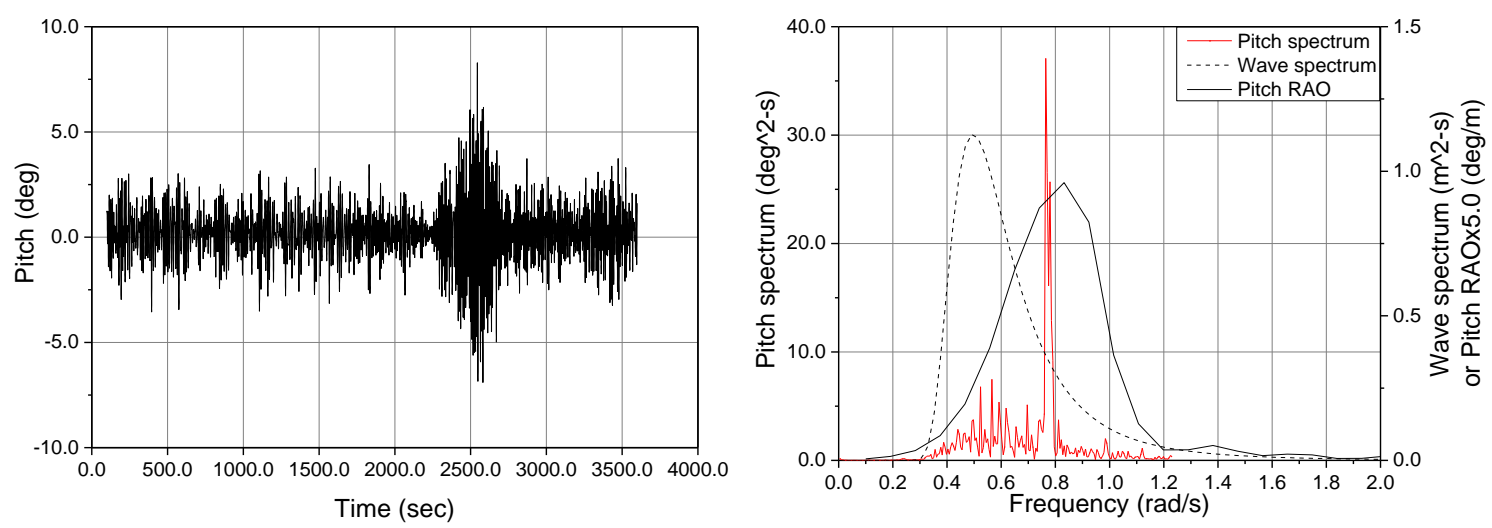

(b) Pitch history, pitch spectrum, wave spectrum, and pitch RAO for a wave direction of $180^{\circ}$

Fig. 9 Time histories, motion spectra, wave spectra, and motion RAOs 
A first step to predict the long-term extreme values of the motion components is to collect the peak and valley data from the motion processes. Then, distribution fitting based on Anderson-Darling test were conducted with a couple of PDFs in which seven different PDFs of generalized extreme, normal, log-normal (two and three parameters, respectively), Weibull (two and three parameters, respectively), and Gumbel distributions were used. All distributions proved to obey three parameter log-normal PDF shown in Eq. (16). Table 6 summarizes all the parameters derived. A second step for the long-term prediction is to calculate the probability of exceedance. Assuming that the probability of exceedance is $1.0 \times 10^{-8}$, the probability values corresponding to the accumulated probability of $1-\left(1.0 \times 10^{-8}\right)$ become the long-term motion components as listed in Table 6. Considering the wave scatter diagram was based on 64 months, insufficient data collection period may not be suitable with the probability of exceedance $1.0 \times 10^{-8}$. The long-term motion components are less conservative than those obtained from the FSA approach.

$$
f(x)=\exp \left[-\frac{1}{2}\left(\frac{\ln (x-\gamma)-\mu}{\sigma}\right)^{2}\right] /[(x-\gamma) \sigma \sqrt{2 \pi}]
$$

where $x$ implies a motion component and $\mu, \sigma$, and $\gamma$ are the mean, standard deviation, and location parameters.

Table 6 Parameters of the log-normal PDFs and long-term values

\begin{tabular}{|c|c|c|}
\hline Parameters & Roll & Pitch \\
\hline$\mu(\mathrm{deg})$ & $5.3251^{\circ}$ & $3.6670^{\circ}$ \\
\hline$\sigma(\mathrm{deg})$ & $0.0206^{\circ}$ & $0.0227^{\circ}$ \\
\hline$\gamma(\mathrm{deg})$ & $-205.470^{\circ}$ & $-38.917^{\circ}$ \\
\hline Long-term $(\mathrm{deg})$ & $25.10^{\circ}$ & $5.54^{\circ}$ \\
\hline
\end{tabular}

\subsection{Comparison of the External Forces}

LashCon [5], which was developed by Det Norske Veritas (DNV) and distributed free, was used to calculate the acceleration and force components based on IMO CSS code [6]. This is denoted by CSS-LC in Table 7. The other results based on the CSS, RULE, FSA, and TSA approaches were calculated using LashingSafety [10]. The tangential acceleration and load components were determined using the derived rotational acceleration component as the input data of LashingSafety.

Table 7 Comparison of the acceleration and force components

\begin{tabular}{|c|c|c|c|c|c|c|}
\hline Case & Item & CSS & CSS-LC & RULE & FSA & TSA \\
\hline \multirow{7}{*}{ Car } & $a_{x}\left(\mathrm{~m} / \mathrm{s}^{2}\right)$ & 2.36 & 2.36 & 0.91 & 2.23 & 1.01 \\
\cline { 2 - 7 } & $a_{y}\left(\mathrm{~m} / \mathrm{s}^{2}\right)$ & 9.49 & 9.28 & 4.28 & 6.66 & 4.29 \\
\cline { 2 - 7 } & $a_{z}\left(\mathrm{~m} / \mathrm{s}^{2}\right)$ & 5.07 & 5.06 & 10.85 & 15.35 & 11.01 \\
\cline { 2 - 7 } & $F_{x}(\mathrm{KN})$ & 2.14 & 2.10 & 0.83 & 2.03 & 0.92 \\
\cline { 2 - 7 } & $F_{y}(\mathrm{KN})$ & 8.64 & 8.40 & 3.89 & 6.06 & 3.91 \\
\cline { 2 - 7 } & $F_{z}(\mathrm{KN})$ & 4.61 & n/a & 9.87 & 13.97 & 10.06 \\
\hline
\end{tabular}




\begin{tabular}{|c|c|c|c|c|c|c|}
\hline & $M_{x}(\mathrm{KN}-\mathrm{m})$ & 6.39 & 6.20 & 2.88 & 4.48 & 2.89 \\
\hline \multirow{4}{*}{ Truck } & $a_{x}\left(\mathrm{~m} / \mathrm{s}^{2}\right)$ & 2.36 & 2.36 & 0.91 & 2.23 & 1.01 \\
\cline { 2 - 7 } & $a_{y}\left(\mathrm{~m} / \mathrm{s}^{2}\right)$ & 9.67 & 9.45 & 4.28 & 6.66 & 4.29 \\
\cline { 2 - 7 } & $a_{z}\left(\mathrm{~m} / \mathrm{s}^{2}\right)$ & 5.89 & 5.89 & 8.63 & 10.93 & 8.72 \\
\cline { 2 - 7 } & $F_{x}(\mathrm{KN})$ & 91.90 & 91.90 & 35.66 & 86.91 & 39.50 \\
\cline { 2 - 7 } & $F_{y}(\mathrm{KN})$ & 377.16 & 368.70 & 166.77 & 259.69 & 167.39 \\
\cline { 2 - 7 } & $F_{z}(\mathrm{KN})$ & 229.76 & $\mathrm{n} / \mathrm{a}$ & 336.39 & 426.45 & 340.25 \\
\cline { 2 - 7 } & $M_{x}(\mathrm{KN}-\mathrm{m})$ & 592.14 & 578.90 & 261.83 & 407.72 & 262.81 \\
\hline
\end{tabular}

The difference in $f_{B G M}$ between the two cases of CSS and CSS-LC may induce a slight difference in the transverse acceleration components $\left(a_{y}\right)$. This also slightly affects the tipping moments $\left(M_{x}\right)$ between the two cases of CSS and CSS-LC. $a_{x}$ and $a_{y}$ (or $F_{x}$ and $F_{y}$ ) by CSS or CSS-LC were predicted conservatively compared to the other cases, whereas CSS or CSS-LC predicted a smaller $a_{z}$ (or $F_{z}$ ). The results by the FSA approach are similar to those by the CSS approach, but the TSA approach estimates $a_{x}$ and $a_{y}$ (or $F_{x}$ and $F_{y}$ ), which are close to ones by the RULE approach.

Considering that $a_{z}$ or $F_{z}$ are not used for the lashing strength components, the CSS approach predicts more conservative external force components than the other cases. This is why the IMO CSS acceleration data might be suitable for ocean-going vessels.

The differences in acceleration between those obtained by TSA and FSA would be due to four reasons. First, whether TSA or FSA is used, we tried to capture the acceleration components using Eqs. (5)-(7), which makes the acceleration calculation process consistent for the approaches of RULE, TSA, and FSA. This means that the long-term roll and pitch angles should be obtained to determine each acceleration component. However, if we directly calculate the long-term roll- and pitch-induced acceleration components from each distribution, they are significantly different from the present approaches. Second, considering FSA depends on linear extrapolation to predict long-terms values, conservancy of the FSAbased results appears to be very natural. Third, we used Ansys Aqwa [12] for TSA and FSA and especially, Aqwa/Naut module was used for TSA in which non-linear Froude-Krylov and hydrostatic forces were estimated under instantaneous incident wave elevation. This is one of the result differences between TSA and FSA. The last cause may be the time increment of TSA. The maximum frequency applied in this study was $4.85 \mathrm{rad} / \mathrm{s}$, which corresponds to a period of about 1.3s. Depending on the method of numerical integration scheme, the magnitude of the time increment may be different. However in order to minimize the possibility of divergence, a time increment of less than 0.2 seconds needs to be applied. 


\section{LASHING STRENGTH}

\subsection{Lashing Strength Formulas}

Fig. 3 presents a sketch for a vehicle secured by a wire. The wire forms two angles of $\alpha$ and $\beta$ on the $y^{\prime} z^{\prime}$-plane and $x^{\prime} y^{\prime}$-plane, respectively. Using the given lashing strength or wire tension, $T$, the longitudinal and transverse lashing strengths of $F_{c x}$ and $F_{c y}$ can be expressed as Eqs. (17)-(18). Let $l$ be a moment arm measured from the tipping point, then the tipping strength becomes Eq. (19), where FS is the factor of safety and 0.9 is suggested by IMO CSS.

$$
\begin{aligned}
& F_{c x}=\mu\left(m g-F_{z}\right)+T_{i} \sum_{i=1}^{n}\left(\mu \sin \alpha_{i}+\cos \alpha_{i} \sin \beta_{i}\right) \\
& F_{c y}=\mu m g+T_{i} \sum_{i=1}^{n}\left(\mu \sin \alpha_{i}+\cos \alpha_{i} \cos \beta_{i}\right) \\
& M_{c x}=\frac{1}{2} C_{y} m g+F S \sum_{i=1}^{n}\left(T_{i} \cdot l_{i}\right)
\end{aligned}
$$

where $\mu$ is the friction coefficient and $n$ is the number of lashing lines on one side.

\subsection{Lashing Strengths of a Car and a Truck}

In this study, it was assumed that four steel cables secure the car and truck, as shown in Fig. 10; the lashing positions are listed in Table 8.

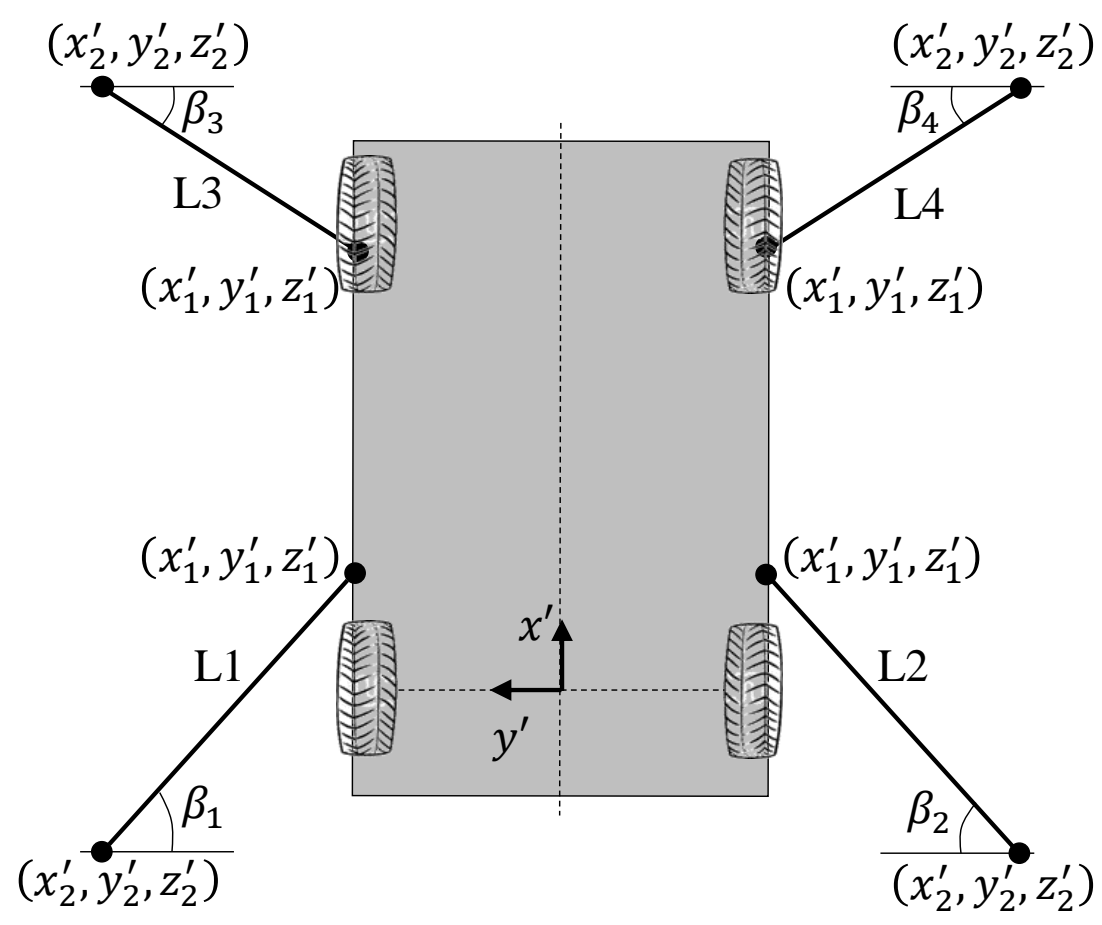

Fig. 10 Vehicle securing plan 
Table 8 Lashing points on vehicle and deck (unit: $m$ )

\begin{tabular}{|c|c|c|c|c|c|c|c|}
\hline \multirow{3}{*}{ Case } & Lash. & $x_{1}^{\prime}$ & $y_{1}^{\prime}$ & $z_{1}^{\prime}$ & $x_{2}^{\prime}$ & $y_{2}^{\prime}$ & $z_{2}^{\prime}$ \\
\hline \multirow{4}{*}{ Car } & L1 & 0.50 & 0.80 & 1.00 & -0.50 & 1.80 & 0.00 \\
\cline { 2 - 8 } & L2 & 0.50 & -0.80 & 1.00 & -0.50 & -1.80 & 0.00 \\
\cline { 2 - 8 } & L3 & 3.10 & 0.80 & 1.00 & 4.10 & 1.80 & 0.00 \\
\cline { 2 - 8 } & L4 & 3.10 & -0.80 & 1.00 & 4.10 & -1.80 & 0.00 \\
\hline \multirow{7}{*}{ Truck } & L1 & 1.00 & 1.25 & 2.00 & -1.00 & 3.25 & 0.00 \\
\cline { 2 - 8 } & L2 & 1.00 & -1.25 & 2.00 & -1.00 & -3.25 & 0.00 \\
\cline { 2 - 8 } & L3 & 11.00 & 1.25 & 2.00 & 13.00 & 3.25 & 0.00 \\
\cline { 2 - 8 } & L4 & 11.00 & -1.25 & 2.00 & 13.00 & -3.25 & 0.00 \\
\hline
\end{tabular}

This securing arrangement makes the lashing angles of $\alpha$ and $\beta$ to be $45^{\circ}$. Each cable was also assumed to be under a tension of $110 \mathrm{kN}(\mathrm{T}=110 \mathrm{kN})$, friction coefficient of $0.3(\mu=0.3)$, and FS of 0.9 .

The lashing strengths should be independent of the external force calculation approaches. On the other hand, longitudinal lashing strength, $F_{c x}$, includes the vertical translational force, as delineated in Eq. (17); thus, slight differences in $F_{c x}$ were found according to the external force estimation approaches.

According to external force calculation cases, Table 9 lists the sum of the securing strengths on one side. One side means that the lashing strengths should be collected at one side because the sum of the lashing strengths on both sides must always be zero. In addition, the load to strength ratios as shown in Table 9 exceed unity, it means failed cargo securing.

Table 9 Comparison of the lashing strengths

\begin{tabular}{|c|c|c|c|c|c|c|}
\hline Case & Item & CSS & CSS-LC & RULE & FSA & TSA \\
\hline \multirow{5}{*}{ Car } & $F_{c x}(\mathrm{kN})$ & 158.64 & 158.00 & 156.39 & 155.16 & 156.33 \\
\cline { 2 - 7 } & $F_{x} / F_{c x}$ & 0.01 & 0.01 & 0.01 & 0.01 & 0.01 \\
\cline { 2 - 7 } & $F_{c y}(\mathrm{kN})$ & 159.35 & 159.00 & 159.35 & 159.35 & 159.35 \\
\cline { 2 - 7 } & $F_{y} / F_{c y}$ & 0.05 & 0.05 & 0.02 & 0.04 & 0.02 \\
\cline { 2 - 7 } & $M_{c x}(\mathrm{kN})$ & 637.17 & 427.00 & 411.61 & 411.61 & 411.61 \\
\cline { 2 - 7 } & $M_{x} / M_{c x}$ & 0.01 & 0.01 & 0.01 & 0.01 & 0.01 \\
\hline \multirow{5}{*}{ Truck } & $F_{c x}(\mathrm{kN})$ & 270.77 & 203.00 & 170.56 & 143.54 & 169.40 \\
\cline { 2 - 7 } & $F_{x} / F_{c x}$ & 0.34 & 0.45 & 0.21 & 0.61 & 0.23 \\
\cline { 2 - 7 } & $F_{c x}(\mathrm{kN})$ & 271.48 & 271.00 & 271.48 & 271.48 & 271.48 \\
\cline { 2 - 7 } & $F_{y} / F_{c y}$ & 1.39 & 1.36 & 0.61 & 0.96 & 0.62 \\
\cline { 2 - 7 } & $F_{c x}(\mathrm{kN})$ & 1108.39 & 1204.00 & 1178.40 & 1178.40 & 1178.40 \\
\cline { 2 - 7 } & $M_{x} / M_{c x}$ & 0.53 & 0.48 & 0.22 & 0.35 & 0.22 \\
\hline
\end{tabular}


Because $F_{c y}$ does not include an external force term, all approaches provide a similar $F_{c y}$, as shown in Table 9. $F_{c x}$ including the external force term, $F_{z}$, varies according to the approaches. $F_{z}$ of the truck was considerably larger than $F_{z}$ of the car, and the difference appears to be very large. When calculating $F_{z}$, Eq. (7) includes only the kinetic components, but CSS-LC showed such a difference including the self-weight term. In the future, IMO CSS should be able to prevent this confusion by providing a guide to the $F_{z}$ calculation method.

Although $M_{c x}$ does not include an external force term, $M_{c x}$ values by CSS and CSSLC are different from each other. As a result of the rigorous analysis of the root causes through manual calculations, there was an error in calculating the moment arm in LashCon [5]. These errors were presumably caused by IMO CSS, providing incorrect figure information. Fig. 11 shows two $\alpha$ values, where $\alpha$ by IMO CSS is not correct so a physically correct $\alpha$ should be used.

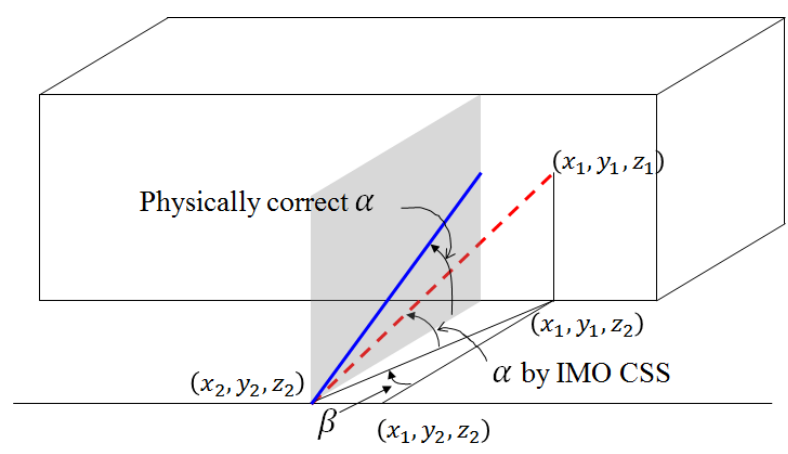

Fig. 11 Correct definition of $\alpha$

\subsection{Discussion on the Lashing Safety}

As depicted in Eqs. (20)-(22), the translational inertia force components ( $F_{x}$ and $F_{y}$ ) and a tipping moment component $\left(M_{x}\right)$, which correspond to the longitudinal and transverse translation and roll directions, respectively, must be less than the cargo securing strengths of $F_{c x}, F_{c y}$, and $M_{c x}$.

$$
\begin{aligned}
& F_{x}<F_{c x} \\
& F_{y}<F_{c y} \\
& M_{x}<M_{c x}
\end{aligned}
$$

The plan for the car securing was determined to be safe, regardless of the external force approaches. On the other hand, when evaluating the lashing safety of the truck using the CSS approach, it is not safe anymore because $F_{y}$ is larger than $F_{c y}$ or $F_{y} / F_{c y}$ is larger than unity as delineated in Table 9. An additional number of lashing wires or an increase in the nominal size of the lashing wire is required in this case.

The acceleration components proposed by IMO CSS is suitable for ocean-going vessels. The RULE or TSA approach is considered to be a more realistic choice because the TSA 
approach used the sea states collected around the Korean coast and level of acceleration based on the TSA approach is similar to that of the RULE approach.

\section{CONCLUSIONS}

A benchmark study on the vehicle securing safety was conducted for a Korean coastal car ferry with a full load displacement of 1,633 tonf in which a car and a truck were stowed at the port-most locations. The acceleration and force components acting on the secured vehicles were derived based on the four different approaches: IMO CSS approach (CSS), rule-based approach (RULE), frequency domain seakeeping analysis approach (FSA), and time domain seakeeping analysis approach (TSA).

The CSS approach uses the acceleration components proposed by IMO CSS. The commonality of the RULE, FSA, and TSA approaches is that they use the same formulae to predict the acceleration components, and the difference is that they apply different roll and pitch angles to these formulae.

In the CSS approach, the acceleration components were taken directly from IMO CSS, and three force components and a tipping moment component were determined.

The FSA approach calculates the motion RAOs directly after frequency response analysis is completed with the ship panel model and sea states collected around Korean coast area. The long-term roll and pitch components for the 20 years design period were $41.07^{\circ}$ and $12.26^{\circ}$, respectively.

The long-term roll and pitch components corresponding to the probability of occurrence of 20 years were predicted using the TSA approach. The motion component histories were obtained from time domain simulations, and the three parameters for log-normal probability density function were captured by collecting the peaks and valleys of the roll and pitch motion components. The long-term values were $25.10^{\circ}$ and $5.54^{\circ}$ for the roll and pitch components, respectively.

To elevate the reliability of CSS approach, LashCon was also used for external force calculations. CSS and CSS-LS showed similar results in all acceleration components. IMO CSS is intended for ocean-going vessels, so the results by the CSS approach were much more conservative than by other approaches. The results by the FSA approach were close to those by the CSS approach, but the results by the TSA approach were close to those by the RULE approach. The RULE and TSA approaches can provide more reasonable force components for coastal car ferries than IMO CSS.

The lashing strength evaluation formulae were taken from IMO CSS. For the car and truck secured symmetrically by four steel wires, the longitudinal, transverse, and tipping strengths were calculated for the approaches. There were the difference between $F_{c x}$ by cases of CSS and CSS-LS, because IMO CSS did not provide a firmly established procedure to predict $F_{z}$.

Further in-depth research will be needed to understand why the FSA and TSA approaches gave different results. In addition, it is necessary to perform FSA and TSA for various car ferries to determine the appropriate roll and pitch angles for Korean coastal waters. 


\section{ACKNOWLEDGMENTS}

This study was financially supported by the Korea Ship Safety Technology Authority and was a part of the project titled 'Manpower training program for ocean energy', funded by the Ministry of Oceans and Fisheries, Korea.

\section{REFERENCES}

[1] DNV-GL, 2016. Rules for Classification, DNV-GL.

[2] Hwang, J. W., Yang, S. K., Hong, C. Y., and Park, J. W., 2004. Development of Lashing Analysis Simulator for Container Vessel, Proceedings of 2004 Spring Conference of the Korean Society of Ocean Engineers(KSOE), Busan, Korea, 90-95.

[3] Shin, S., H., Hwang, G., H., 2014. Development of the Container Securing Program for Large Container Carriers, Journal of the Society of Naval Architects of Korea, 51, 5, 362-368. https://doi.org/10.3744/SNAK.2014.51.5.362

[4] Turnbull, S., R., Dawson, D., 1997. The securing of Rigid Semi-Trailers on Roll-on/Roll-off Ships, Journal of Mechanical Sciences, 39, 1, 1-14. https://doi.org/10.1016/0020-7403(96)00021-5

[5] Det Norske Veritas(DNV), 2003. LashCon IMO User Guide. [Online] Available at: http://www.dnv.com [Accessed September 2015].

[6] International Maritime Organization (IMO), 2012. Code of Safe Practice for Cargo Stowage and Securing.

[7] Jiao, J., Sun, S., and Ren, H., 2016. Predictions of wave induced ship motions and loads by large-scale model measurement at sea and numerical analysis, Brodogradnja: Teorija i praksa brodogradnje i pomorske tehnike, 67, 2, 81-100. https://doi.org/10.21278/brod67206

[8] Martić, I., Degiuli, N., and Ćatipović, I., 2015. Added resistance in waves of intact and damaged ship in the Adriatic Sea. Brodogradnja: Teorija i praksa brodogradnje i pomorske tehnike, 66, 2, 1-14.

[9] Korea Shpping Association (KSA), 2011. Information on Coastal Ferry Companies.

[10] Jo, H., Choung, J., and Lee, K., 2016. Force Equilibrium-Based Safety Assessment System for Cargo Securing of Car Ferries, Proceedings of 26th Internal Ocean and Polar Engineering Conference(ISOPE), Rhodes, Greece, 4, 715-722.

[11] Kim, J. H., 2008. Nonlinear Waves and Offshore Structures. World Scientific. https://doi.org/10.1142/4906

[12] Ansys, 2015. Aqwa User Manual, USA.

Submitted: $\quad$ 09.04.2018. Joonmo Choung, jmchoung@inha.ac.kr

Department of Naval Architecture and Ocean Engineering, Inha University,

Accepted: $\quad$ 22.07.2019. Incheon, Republic of Korea

*Se-Min Jeong, smjeong@ @hosun.ac.kr

Department of Naval Architecture and Ocean Engineering, Chosun

University, Gwangju, Republic of Korea

$*$ : Corresponding author 